\title{
Non-Operative Management of Thoracoabdominal Gunshot Injury: Thirteen Unusual Cases
}

\author{
Zubeyir Bozdaga, d, Ahmet Turkoglua, Metehan Gumusa, Hatice Gumus ${ }^{\mathrm{b}}$, Abdullah Boyuk ${ }^{\mathrm{a}}$, \\ Hekim Kuzuc ${ }^{\mathrm{c}}$ Ibrahim Halil Tacyildiz ${ }^{\mathrm{a}}$
}

\begin{abstract}
Background: Recently, the use of a surgical approach in injured patients has begun to be increasingly limited to unstable patients. Advances in imaging techniques and developments in intensive care have increased the applicability of non-operative treatment. Here, we aimed to present our clinical experience with different approaches in some patients.
\end{abstract}

Method: Thirteen inpatients who had thoracoabdominal gunshot injuries but did not undergo emergency surgery between 2009 and 2014 were retrospectively evaluated.

Results: Of the patients, nine $(69.2 \%)$ were male and the mean age was $32.6 \pm 9.7$ years. The mean trauma-treatment interval was 51.2 \pm 15.8 minutes. No surgical procedure was performed in 10 patients, four of whom had tangential injury. Diaphragmatic repair was performed in three patients after stabilization of solid organ injuries. The splenic and liver injuries were allowed to resolve itself through nonoperative management, and there was no rush to repair the diaphragm until the splenic and liver recovery occurred. Four patients with tangential injury were shown not to have penetration of the abdominal cavity. Two pregnant patients, one with liver injury and the other with retroperitoneal injury, were successfully treated non-operatively.

Conclusions: In centers that provide advanced conditions for emergency surgery, a conservative approach can be performed successfully in selected thoracoabdominal gunshot wound patients, including pregnant patients and those with splenic injuries. Tangential injuries can be managed non-operatively after penetration of cavities is ruled out. When diaphragmatic hernia is accompanied by liver or splenic injury, diaphragmatic repair can be delayed until these injures are re-

Manuscript accepted for publication October 08, 2015

${ }^{a}$ Department of General Surgery, Faculty of Medicine, Dicle University, Diyarbakir, Turkey

${ }^{b}$ Department of Radiology, Faculty of Medicine, Dicle University, Diyarbakir, Turkey

${ }^{\mathrm{c} D e p a r t m e n t}$ of General Surgery, Gercus State Hospital, Gercus, Turkey

${ }^{\mathrm{d} C}$ Corresponding Author: Zubeyir Bozdag, Department of General Surgery, Medical Faculty, Dicle University, Yenisehir, 21280 Diyarbakir, Turkey. Email: zubeyirbozdag@gmail.com

doi: http://dx.doi.org/10.14740/jcs281w stricted themselves.

Keywords: Non-operative management; Thoracoabdominal; Gunshot; Injury

\section{Introduction}

In the treatment of trauma patients, surgery is still a very important step. However, surgery has some drawbacks, such as more bleeding and the need for blood for patients, possible requirements for repeated surgery, incisional hernia, infection, adhesions, unnecessary organ resection, a second trauma to trauma patients, and cosmetic concerns. Therefore, the use of the surgical approach has begun to be increasingly limited to unstable patients $[1,2]$. The ability to obtain detailed information about the location and severity of injury owing to advances in imaging techniques and development in intensive care increase the applicability of non-operative treatment. Consequently, non-operative treatment, which is standard for blunt solid organ injuries, has begun to be applied in penetrating thoracoabdominal injuries in stable patients [3]. Recently, although non-operative management is beginning to be used in the treatment of selected cases $[4,5]$, surgery continues to be the primary treatment approach in the gunshot wounds. To clarify the criteria in this issue, data from high volume advanced trauma centers are needed.

Here, in this study, we aimed to present our clinical experience with different approaches in some patients and to question the absolute necessity of exploration in this approach, which is applicable with good management in only appropriately selected patients.

\section{Materials and Methods}

Thirteen inpatients who had thoracoabdominal gunshot injuries but did not undergo emergency surgery between 2009 and 2014 were included in the study. The demographic characteristics of the patients, as well as the trauma-treatment interval (TTI), diagnostic methods, length of hospital stay, organ injuries, and therapy methods were retrospectively evaluated from the hospital records. According to our clinic algorithm, unsta- 


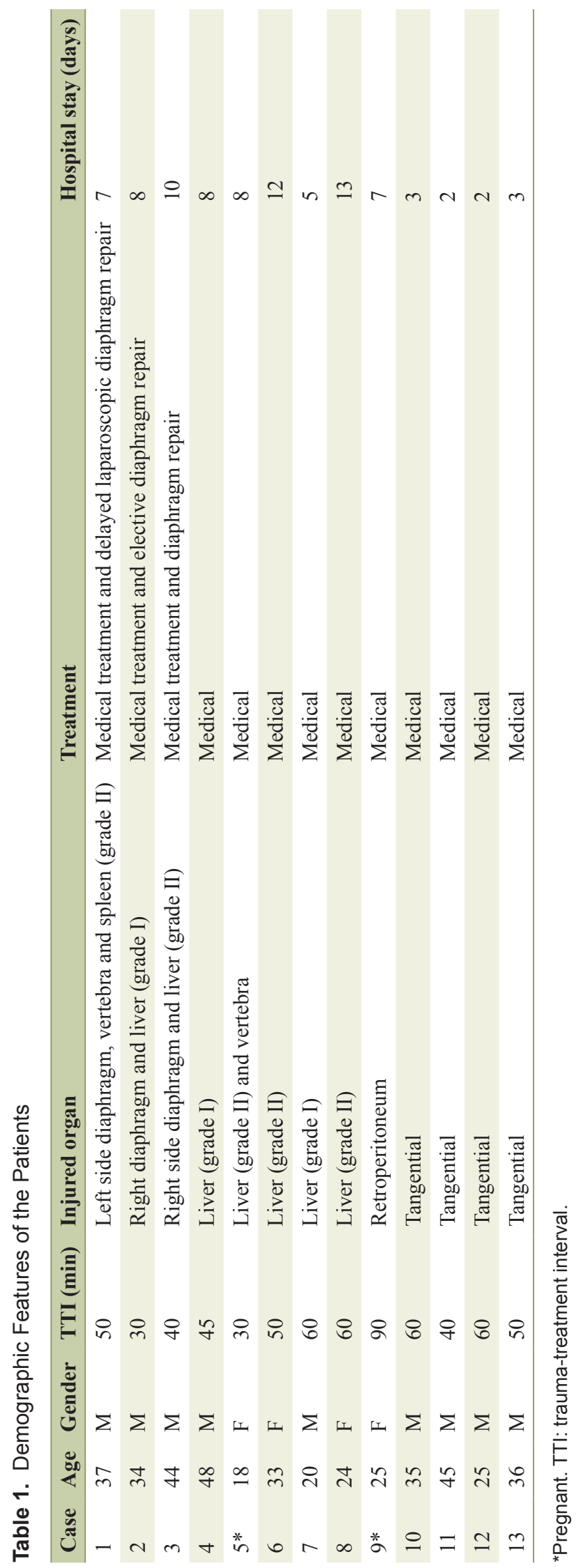

ble patients undergo emergency surgery, but in stable patients, the decision to operate is made after the patient's evaluation with imaging.

\section{Results}

Of the patients, nine $(69.2 \%)$ were male and four $(30.8 \%)$ were female. The mean age was $32.6 \pm 9.7$ years (range, $18-48$ years) and the mean TTI was $51.2 \pm 15.8(30$ - 90) min. A pregnant patient, who was referred to our hospital from another center, was admitted to our hospital $8 \mathrm{~h}$ after initial trauma. The general characteristics of the patients are summarized in Table 1. Ultrasound (US) and/or computed tomography (CT) were performed in all patients (Fig. 1). All patients were hemodynamically stabile $(>90 \mathrm{~mm} \mathrm{Hg}$ systolic blood pressure and $>60$ $\mathrm{mm} \mathrm{Hg}$ mean arterial pressure) with or without minimal fluid resuscitation. No patients had demonstrable peritoneal signs on abdominal examination or any intraperitoneal or retroperitoneal injuries on $\mathrm{CT}$ scans requiring surgical intervention. The liver $(53.8 \%)$ and diaphragm $(23.1 \%)$ were the most frequently damaged organs, and there was tangential injury in four patients. Two patients had vertebral injuries without motor or sensation loss. Of seven liver injury patients, three were grade I and four were grade II. Two patients, one with liver injury and the other with retroperitoneal injury, were pregnant (Fig. 1).

No surgical procedure was performed in 10 patients, though diaphragmatic repair was performed in three patients after stabilization for solid organ injury. Two patients with liver injury were referred to the thoracic surgery unit for elective thoracoscopic diaphragmatic repair, while elective laparoscopic repair was performed in the patient with splenic injury. The splenic injury was allowed to resolve itself through non-operative management, and there was no rush to repair the diaphragm until splenic recovery occurred. The patient was operated laparoscopically on 3 days after the accident. During surgery, two diaphragmatic defects were repaired laparoscopically (Fig. 2). A pregnant patient referred from another hospital was admitted to our hospital $8 \mathrm{~h}$ after the accident. Her vital signs were stable and she had no evidence on imaging indicating a requirement for operative intervention, so it was decided to manage her care non-operatively. A second pregnant patient with retroperitoneal injury was managed non-operatively (Fig. 1). Both were monitored closely, particularly to avoid hypotension.

No deterioration in the stability of the patients was seen during management in the intensive care unit. None of the patients required a blood transfusion. The mean length of hospital stay was $6.8 \pm 3.6$ days (range, 3 - 13 days). While patients with tangential injury had the shortest length of hospital stay, patients with liver or spleen injury had longer lengths of hospital stay.

\section{Discussion}

Despite the wide range of applications in the non-operative management of blunt thoracoabdominal trauma patients, laparotomy is a common practice in gunshot wounds. However, 


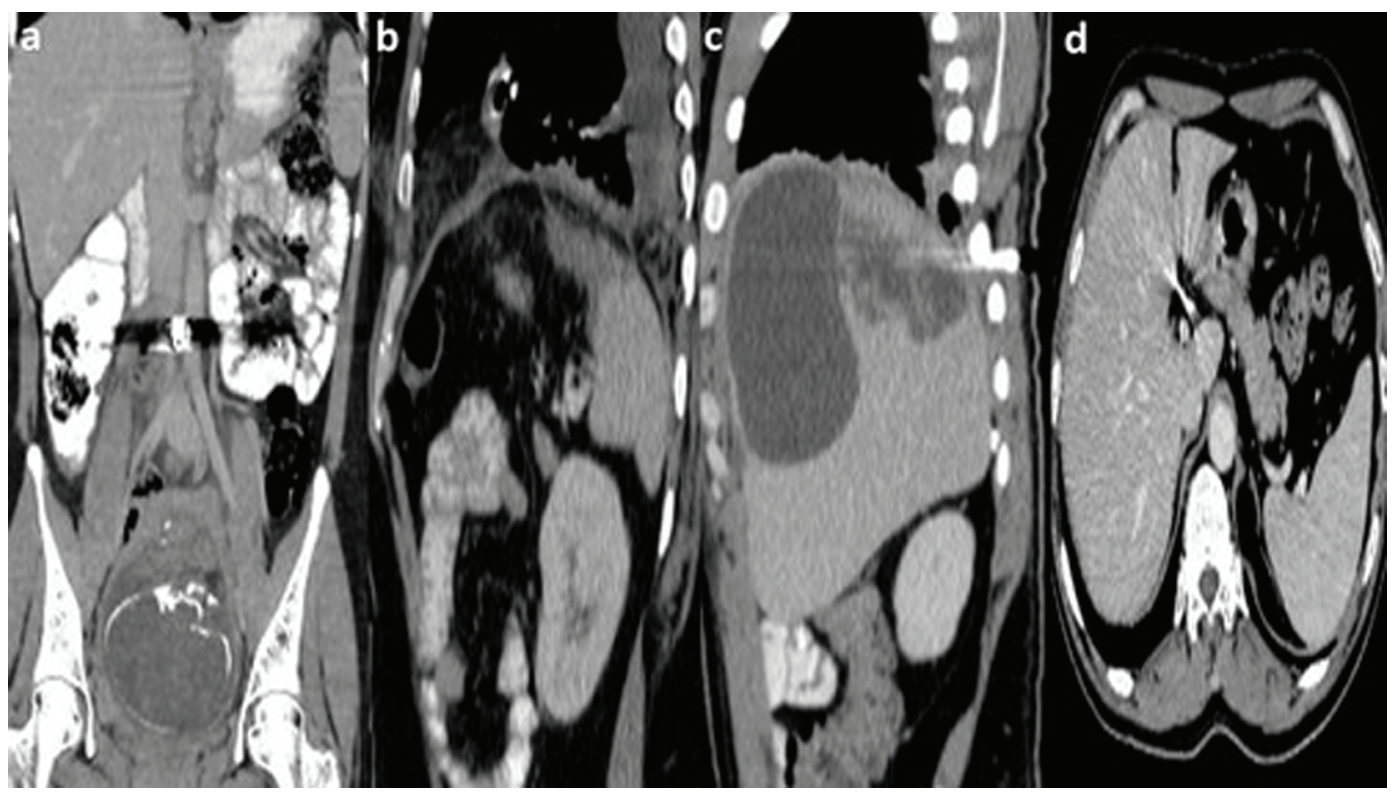

Figure 1. (a) In an 8-month pregnant patient with gunshot wound to abdomen, the coronal reformat CT shows a bullet in just the right neighborhood of the abdominal aorta. There is no abdominal parenchymal organ injury. (b) In a patient with gunshot wound to the thoracoabdomen, the sagittal reformat CT demonstrates superior splenic laceration. There are small retroperitoneal fat herniations through a posterior left diaphragm defect (Bochdalek hernia) and minimal fluid and injury in the left hemithorax. (c) The sagittal reformat CT of a patient with gunshot wound to the abdomen shows subcapsular hematoma and laceration in the right liver. There is a bullet next to a posterior rib. (d) The axial CT of a patient with gunshot wound to the abdomen shows a bullet in the periportal area. The hepatic artery and portal vein are patent. There is no abdominal organ injury.

it is not considered to be an absolute requirement for every patient. The most appropriate treatment option is an individualized plan for each patient. A conservative approach requires good imaging capabilities and a fully equipped intensive care unit [6]. Hemodynamic stability with or without minimal fluid resuscitation, no demonstrable peritoneal signs on abdominal examination, the absence of any intraperitoneal or extraperitoneal injuries requiring operative intervention, and not being under the influence of alcohol and drugs were criteria for nonoperative treatment [5-9]. In our study, no patients had intra- peritoneal or extraperitoneal injuries requiring surgical intervention. Additionally, no patients required blood transfusion.

When using non-invasive methods with gunshot wounds, the degree of parenchymal organ damage, hollow organ injuries, diaphragmatic injuries, and the degree of lung damage may be difficult to determine. Therefore, patients to be treated with non-operative management must be well chosen. The selection of patients is the most difficult aspect of non-operative treatment in patients with gunshot injuries [7-9].

Though some clinical signs may be absent on presentation,

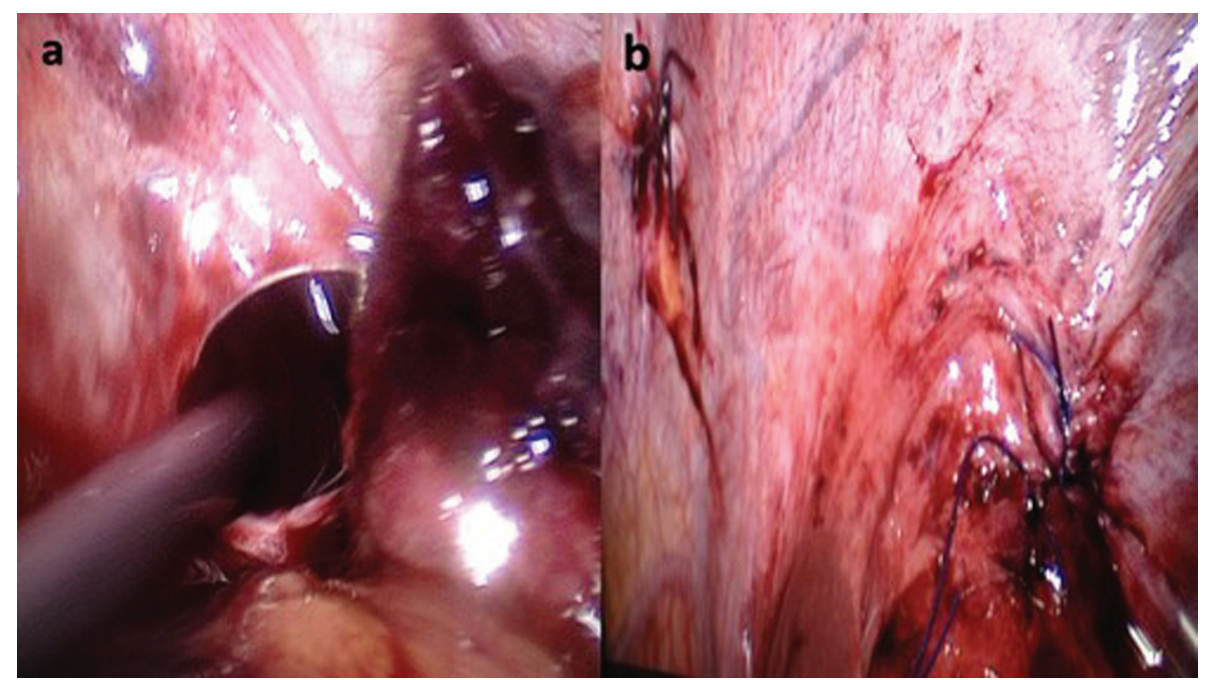

Figure 2. (a) Defect of the diaphragm in laparoscopic exploration. (b) Repaired two diaphragmatic defects. 
they may appear later. In trauma patients, the TTI is important in assessing the patient's stability. In patients who are admitted early, despite the problems in the abdomen, peritonitis findings may not be detected. In some cases, imaging also is not helpful. In many patients, delayed admission causes morbidity and even mortality $[10,11]$, but as in our case, it can be helpful in assessing the stability of patients. In this study, although the trauma-admission interval was $8 \mathrm{~h}$ in one patient, this pregnant patient with liver injury was still stable and had no absolute indication for surgery. So, we encouraged further studies, and she avoided the detrimental effects of surgery. When the decision is made to avoid emergency surgery, the most important thing is close clinical examination. Patients are observed carefully with serial abdominal examinations.

Because every surgical and anesthetic procedure can be harmful to both mother and fetus, non-operative management of pregnant trauma patients has a special importance. As the uterus increases in size, it expands out of the pelvis and fills the abdominal cavity. Due to the thick density of the uterine musculature, maternal death probability decreases. Abdominal gunshot wounds cause injuries in up to $60-70 \%$ of the fetuses, which has harmful effects on maternal health. Therefore, before the decision for non-operative management, complete evaluations including the uterus and fetus of these patients should be performed in order to save the pregnancy $[12,13]$. There was no problem in gynecological assessment in our cases.

In hemodynamically stable patients with blunt splenic and liver injury, non-operative approach is regarded as the gold standard [14]. Additionally, it has been shown that a nonoperative approach is cost-effective. In solid organ injuries due to gunshot wounds, the standard approach is exploration [15]. However, it was reported that a non-operative approach is also possible in carefully selected patients. Navsaria et al [16] reported that in 1,106 patients, splenic injury in eight and liver injury in 79 were managed non-operatively. The success rate for liver injury was $91.4 \%$ in their study. Other studies reported that non-operative management is a safe procedure for carefully selected grade 1-2 liver injury $[8,9,16]$. In our study, seven patients had liver injury; four of them had isolated liver injury, while two had diaphragm injury and one had vertebral injury in addition to liver injury. All were successfully managed non-operatively.

In splenic injury due to gunshot injuries managed conservatively, a limited number of cases have been reported in the literature, and their success rate is lower than the success rate for liver injury (62\% vs. 91.4\%) [16]. In this study, one patient had splenic and diaphragmatic injury. After the spleen injury was stabilized conservatively, the diaphragm was repaired without splenectomy 3 days after the accident.

Diaphragmatic injuries are treated surgically. However, there are several differences between right and left injuries. Right side diaphragmatic injury has a lower herniation ratio than the left side because the liver creates barrier for herniation. Also, it was seen that defects in the left side are more prone to expand over time $[17,18]$. Posterior-anterior chest radiography, ultrasound, CT, and diagnostic laparoscopy are used for the detection of diaphragmatic injury. Of all, laparoscopy has the highest diagnostic value; it can also be used in the treatment $[19,20]$. Shah et al [21] reported that diaphragm in- jury could be diagnosed preoperatively in only $43.4 \%$ of cases. Therefore, even if CT is negative, diagnostic laparoscopy is suggested, especially in left thoracoabdominal injury [22]. In patients with diaphragmatic injury accompanied by splenic or liver injury, the reason for delaying the laparoscopy is to limit injuries to the spleen or liver. The optimal timing of repair for isolated diaphragmatic injury is controversial. If emergency surgery for accompanying liver or spleen injury is not needed, diaphragmatic repair can be delayed $[22,23]$. In this study, in three patients with diaphragmatic hernia accompanied by liver or spleen injury, diaphragmatic repair was delayed. Therefore, this approach enabled us to avoid possible morbidity of an unnecessary surgical procedure.

Tangential injuries are known as injuries located especially in the lateral thoracoabdominal, flank, or suprapubic regions that do not penetrate the parietal peritoneum. Studies show that patients thus injured can be managed non-operatively after ruling out penetration of the cavities. However, it is known that the ballistic impact of some projectiles causes damage to the surrounding tissue, forming a temporary cavity approximately 12 times greater than permanent cavity. Therefore, besides investigating the trajectory of the bullet, hollow viscus injury should also be specifically investigated [24, 25]. In this study, there were four patients with tangential injury. Abdominal CT performed showed that the intra-abdominal organs were intact in all patients. The patients were kept under observation for at least $48 \mathrm{~h}$.

An emergency physician should not also forget the potential complications of a non-operative therapy regime. Missing hollow viscus injury with subsequent sepsis due to fecal contaminations is a serious problem which in the case could cause major problems with pregnant patients. Nevertheless complication rates of a conservative management in selected patients are no greater than those of surgical approach, especially in liver injuries [26]. Delayed treatment of a complication may be fatal due to abdominal sepsis or bleeding. Therefore, nonoperative management of gunshot injuries should be employed only in centers that have appropriate facilities to deal with potential complications. An extensively evaluated CT scanning may prevent operative delays and related complications [27]. No complication due to non-operative management was observed in our case series. This may be because of our carefully selection of the patients candidate for the non-operative management among all trauma patients.

In conclusion, surgery should not be considered to be an absolute requirement for each patient in gunshot wounds. However, patient selection should be made carefully, and a special schedule should be determined for each patient. A conservative approach has a need for good imaging and a fully equipped intensive care unit. It also requires experienced surgeons and an operating room ready for emergency surgery 24 $\mathrm{h}$ a day. In centers that are able to provide these conditions, a conservative approach can be performed successfully in selected thoracoabdominal gunshot wound patients, including pregnant patients. When diaphragmatic hernia is accompanied by liver or spleen injuries, diaphragmatic repair can be delayed until injures limited themselves. For the creation of certain criteria in this respect, which has limited data, there is a need to collect data from several centers. 


\section{Limitations}

The study was designed retrospectively and has limited data. Patients were not homogeneous with respect to type of injury and missile.

\section{Conflict of Interest}

Zubeyir Bozdag and other co-authors have no conflict of interest.

\section{References}

1. Gauer JM, Gerber-Paulet S, Seiler C, Schweizer WP. Twenty years of splenic preservation in trauma: lower early infection rate than in splenectomy. World J Surg. 2008;32(12):2730-2735.

2. Morrison JE, Wisner DH, Bodai BI. Complications after negative laparotomy for trauma: long-term followup in a health maintenance organization. J Trauma. 1996;41(3):509-513.

3. Jansen JO, Inaba K, Resnick S, Fraga GP, Starling SV, Rizoli SB, Boffard KD, et al. Selective non-operative management of abdominal gunshot wounds: survey of practise. Injury. 2013;44(5):639-644.

4. Fikry K, Velmahos GC, Bramos A, Janjua S, de Moya M, King DR, Alam HB. Successful selective nonoperative management of abdominal gunshot wounds despite low penetrating trauma volumes. Arch Surg. 2011;146(5):528532.

5. Gumus M, Gumus H, Yildirgan I. Nonoperative Treatment Of Gunshot Wound To The Liver. MJAU. 2002;34:97-99.

6. Singh N, Hardcastle TC. Selective non operative management of gunshot wounds to the abdomen: a collective review. Int Emerg Nurs. 2015;23(1):22-31.

7. Demetriades D, Velmahos G, Cornwell E, 3rd, Berne TV, Cober S, Bhasin PS, Belzberg H, et al. Selective nonoperative management of gunshot wounds of the anterior abdomen. Arch Surg. 1997;132(2):178-183.

8. Demetriades D, Gomez H, Chahwan S, Charalambides K, Velmahos G, Murray J, Asensio J, et al. Gunshot injuries to the liver: the role of selective nonoperative management. J Am Coll Surg. 1999;188(4):343-348.

9. Pal KM, Khan A. Nonoperative management of penetrating liver trauma. Injury. 2000;31(3):199-201.

10. Gumus M, Kapan M, Onder A, Boyuk A, Girgin S, Tacyildiz I. Factors affecting morbidity in penetrating rectal injuries: a civilian experience. Ulus Travma Acil Cerrahi Derg. 2011;17(5):401-406.

11. Sikhondze WL, Madiba TE, Naidoo NM, Muckart DJ. Predictors of outcome in patients requiring surgery for liver trauma. Injury. 2007;38(1):65-70.

12. Turkoglu A, Gumu M, Bozdag Z, Zengin Y, Findik FM. Nonoperative Management In a Pregnant Patient With Gunshot Injury: Case Report. JCEI. 2014;5(4):623-625.
13. Petrone P, Asensio JA. Trauma in pregnancy: assessment and treatment. Scand J Surg. 2006;95(1):4-10.

14. Boyuk A, Gumus M, Onder A, Kapan M, Aliosmanoglu I, Taskesen F, Ar?kanoglu Z, et al. Splenic injuries: factors affecting the outcome of non-operative management. Eur J Trauma Emerg Surg. 2012;38(3):269-274.

15. Bruce PJ, Helmer SD, Harrison PB, Sirico T, Haan JM. Nonsurgical management of blunt splenic injury: is it cost effective? Am J Surg. 2011;202(6):810-815; discussion 815-816.

16. Navsaria PH, Nicol AJ, Edu S, Gandhi R, Ball CG. Selective nonoperative management in 1106 patients with abdominal gunshot wounds: conclusions on safety, efficacy, and the role of selective CT imaging in a prospective single-center study. Ann Surg. 2015;261(4):760-764.

17. Zierold D, Perlstein J, Weidman ER, Wiedeman JE. Penetrating trauma to the diaphragm: natural history and ultrasonographic characteristics of untreated injury in a pig model. Arch Surg. 2001;136(1):32-37.

18. De Rezende Neto JB, Guimaraes TN, Madureira JL, Jr., Drumond DA, Leal JC, Rocha A, Jr., Oliveira RG, et al. Non-operative management of right side thoracoabdominal penetrating injuries--the value of testing chest tube effluent for bile. Injury. 2009;40(5):506-510.

19. Okur MH, Uygun I, Arslan MS, Aydogdu B, Turkoglu A, Goya C, Icen M, et al. Traumatic diaphragmatic rupture in children. J Pediatr Surg. 2014;49(3):420-423.

20. Mjoli M, Oosthuizen G, Clarke D, Madiba T. Laparoscopy in the diagnosis and repair of diaphragmatic injuries in left-sided penetrating thoracoabdominal trauma: laparoscopy in trauma. Surg Endosc. 2015;29(3):747-752.

21. Shah R, Sabanathan S, Mearns AJ, Choudhury AK. Traumatic rupture of diaphragm. Ann Thorac Surg. 1995;60(5):1444-1449.

22. Bozkurt MA, Kalayci MU, Dogan M, Karabulut M, Alis H. Sol diafram yaralanmasi tespiti nasil yapilmalidir? Genel Tip Derg. 2012;22(4):121-124.

23. Turkoglu A, Gumus N, Bozdag Z, Kuzu H, Zengin Y. A Planned Delayed Laparoscopy in a Gunshot Injury Case With Spleen and Diaphragmatic Demage. Dicle Med J. 2014;41(4): 758-759.

24. Tien HC, van der Hurk TW, Dunlop MP, Kropelin B, Nahouraii R, Battad AB, van Egmond T. Small bowel injury from a tangential gunshot wound without peritoneal penetration: a case report. J Trauma. 2007;62(3):762-763; discussion 763-764.

25. Gumus M, Boyuk A, Gumus H, Kapan M, Onder A. Atypical Trajectory of a Thoracoabdominal Gunshot Injury without Penetration. Rom J Leg Med. 2010;18:203206.

26. Omoshoro-Jones JA, Nicol AJ, Navsaria PH, Zellweger R, Krige JE, Kahn DH. Selective non-operative management of liver gunshot injuries. Br J Surg. 2005;92(7):890-895.

27. Velmahos GC, Constantinou C, Tillou A, Brown CV, Salim A, Demetriades D. Abdominal computed tomographic scan for patients with gunshot wounds to the abdomen selected for nonoperative management. J Trauma. 2005;59(5):1155-1160; discussion 1160-1151. 